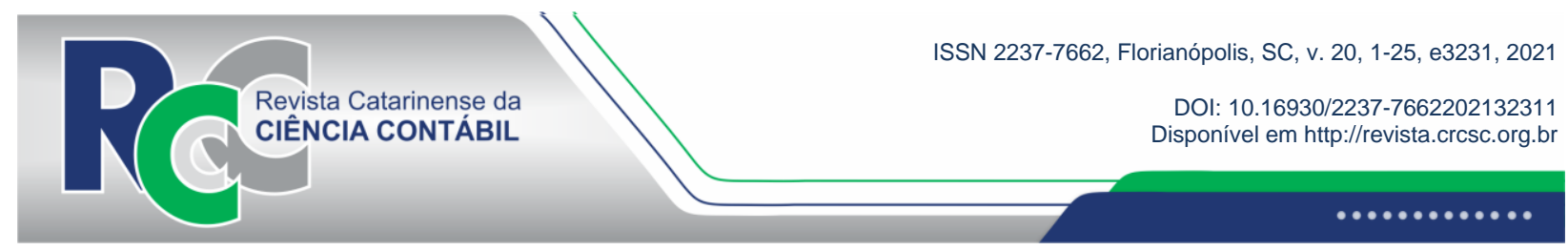

\title{
ANÁLISE DA DIVULGAÇÃO DAS TESES EM CONTABILIDADE NO BRASIL
}

\section{ANALYSIS OF THE DISSEMINATION OF ACCOUNTING THESES IN BRAZIL}

\author{
ALEFI DOS SANTOS PEREIRA \\ Universidade Federal de Mato Grosso do Sul. \\ Endereço: Av. Sen. Filinto Müler, 1015 | Cidade Universitária | \\ 79046-460 | Campo Grande/MS | Brasil. \\ (D) https://orcid.org/0000-0001-8439-9255 \\ alefi19.santos@gmail.com
}

\author{
ELISABETH DE OLIVEIRA VENDRAMIN \\ Universidade Federal de Mato Grosso do Sul. \\ Endereço: Av. Sen. Filinto Müler, 1015 | Cidade Universitária | \\ 79046-460 | Campo Grande/MS | Brasil. \\ (D) https://orcid.org/0000-0002-9082-2256 \\ elisabeth.vendramin@ufms.br
}

\section{RESUMO}

O objetivo da presente pesquisa foi analisar a divulgação do conhecimento científico gerado nas teses em Ciências Contábeis no Brasil defendidas nos programas de pós-graduação stricto sensu, entre 2009 e 2018. É um estudo com abordagem qualitativa de caráter descritivo, a partir de pesquisa bibliográfica e documental. Para a coleta de dados, utilizou-se dos repositórios de teses e dissertações e regimento dos programas de pós-graduação em contabilidade no Brasil, além do acervo disponível na plataforma lattes do CNPq. Foram analisados os dados registrados no currículo lattes dos doutores titulados em cada programa de pós-graduação. Os dados demonstram que as instituições de maior relevância em projetos de pesquisas, a FEA USP e FURB estão entre as que mais publicam. Constatou-se que as teses estudadas apresentam divulgação, em grande parte, por anais em congresso e eventos acadêmicos. Dentre os artigos publicados em periódicos científicos, 38,0\% foram em revista de Qualis A2, B1 e B2, em que a FEA USP foi a universidade responsável pelo maior número de publicações. Verificou-se, ainda, que dos 302 artigos publicados com relação direta às teses dos doutorados, houve 2.382 citações em outras pesquisas científicas. Do total geral das teses defendidas e suas respectivas publicações em artigos periódicos, verifica-se que a região Sudeste foi a que obteve os maiores índices de publicações. Observou-se uma limitação em repassar esses dados da área contábil para a sociedade em geral, e uma das sugestões é modificar a forma de divulgação e da escrita, como por exemplo, em formato de palestras e workshops.

Palavras-chave: Pós-graduação. Ciências Contábeis. Pesquisa. Divulgação.

Editado em português e inglês. Versão original em português.

Recebido em 1/12/2021. Revisado em 16/12/2021. Aceito em 20/12/2021 pelos Prof. Dr. Sérgio Murilo Petri (Editor-Chefe) e Prof. Dr. Sandro Vieira Soares (Editor Adjunto). Publicado em 29/12/2021.

Copyright () 2021 RCCC. Todos os direitos reservados. É permitida a citação de parte de artigos sem autorização prévia, desde que identificada a fonte. 


\begin{abstract}
The purpose of this research was to analyze the dissemination of scientific knowledge generated in theses in Accounting Sciences in Brazil defended in stricto sensu graduate programs, between 2009 and 2018. It is a study with a qualitative approach of descriptive character, based on bibliographical and documentary. For data collection, the repositories of theses and dissertations and the regulations of graduate accounting programs in Brazil were used, in addition to the collection available on the CNPq lattes platform. Data recorded in the lattes curriculum of PhDs in each graduate program were analyzed. The data show that the most relevant institutions in research projects, FEA USP and FURB are among those that publish the most. It was found that the theses studied are largely disseminated through annals in congresses and academic events. Among the articles published in scientific journals, 38.0\% were in a Qualis A2, B1, and B2 journal, in which FEA USP was the university responsible for the largest number of publications. It was also found that of the 302 articles published with direct relation to doctoral theses, there were 2,382 citations in other scientific research. Of the grand total of theses defended and their respective publications in periodical articles, it appears that the Southeast region was the one with the highest rates of publications. There was a limitation in passing on these data from the accounting area to society in general, and one of the suggestions is to change the form of disclosure and writing, for example, in the format of lectures and workshops.
\end{abstract}

Keywords: Graduate studies. Accounting. Research. Disclosure.

\title{
1 INTRODUÇÃO
}

A alta competitividade e a precarização no mercado de trabalho têm afetado os jovens diplomados brasileiros. Bardagi et al. (2006) apontam que, diante do mercado de trabalho, a insegurança dos alunos ao final do curso e o desenvolvimento das atividades profissionais fazem com que os mesmos busquem recursos e ferramentas que possam ajudá-los a encontrar um emprego. Entre esses recursos, a pós-graduação stricto sensu (mestrado e doutorado) é percebida como uma das principais opções.

De acordo com o Parecer Sucupira $n^{\circ}$ 977/65, a pós-graduação surge como uma necessidade de treinamento avançado na universidade moderna. $\mathrm{O}$ aprofundamento a curto prazo possibilitará ao aluno a aquisição de elevada competência profissional científica ou técnica, que não está disponível no âmbito dos cursos de graduação. Ressalta-se que, a pós-graduação no Brasil tem contribuído para um maior conhecimento dos problemas que emergem em diversos âmbitos na sociedade, bem como para a qualificação de expressivo quadro de profissionais nas áreas de Ensino, Gestão e Pesquisa (Severino, 2006; Borges, 2008).

Em 1981, pelo Decreto n 86.791, a Coordenação de Aperfeiçoamento de Pessoal de Nível Superior (Capes) foi reconhecida como órgão responsável pela elaboração do Plano Nacional de Pós-Graduação Stricto Sensu, cabendo-lhe elaborar, avaliar, acompanhar e coordenar as atividades relativas ao ensino superior. Porém, desde 1960 a Capes tem criado Planos Nacionais de Pós-graduação (PNPG) cujo objetivo é definir novas diretrizes, estratégias e metas para dar continuidade e avançar na política brasileira de pós-graduação e recomendações de pesquisas (Nobre \& Freitas, 2017).

Tais debates se intensificaram pelo fato de a sociedade não ter conhecimento de tudo que é desenvolvido dentro das universidades, principalmente, por serem os principais financiadores das pesquisas. Com base em todo esse processo de reestruturação do sistema da ciência, ressaltase a importância de divulgar ao público os resultados das pesquisas realizadas no âmbito acadêmico, pois, as publicações são uma maneira de contribuir para a produção e difusão do 
conhecimento científico, além de ser um critério para a distribuição de financiamento em programas de pós-graduação (Moutinho, Cesarino \& Novaes, 2019).

Diante dessa problemática, a nova metodologia de avaliação da Capes (2017-2020) traz inovação, onde será possível medir outros pontos como o impacto e relevância para a sociedade, além da inovação produzida, internacionalização e inserção regional. Apesar da importância dos parâmetros e indicadores para se ter uma métrica eficaz, acredita-se que será uma tarefa complexa, uma vez que é necessário considerar a especificidade e os objetivos de cada área. No entanto, julga-se importante ter como direção que o impacto social é um conceito que exprime a utilidade e os benefícios, que de fato, os resultados gerados pelos Programas representam para a sociedade (Tanaka, 2021).

Tratando-se da área contábil, Martins (2007), Murcia e Borba (2008) e Dantas et al. (2011) afirmam que os programas de pós-graduação em contabilidade estão aumentando significativamente, fato que é endossado pelo aumento no número de produções e periódicos científicos, bem como maior número de eventos na área. Quanto aos motivos que levaram ao crescimento da produção científica em contabilidade, Martins (2007) diz que isso se deu pelo aumento no número de programas em nível de mestrado, doutorado e especialização, criação de seminários, encontros e congressos, além da quantidade de periódicos com editorial exclusivo para a área.

Dias, Barbosa Neto e Cunha (2011), em reflexão sobre a comunicação do conhecimento científico, afirmam que os congressos são importantes meios de comunicação científica, pois proporcionam uma troca de experiências, em que o aumento do conhecimento depende da abrangência de sua comunicação. Além dos eventos, as publicações em periódicos especializados proporcionam a exteriorização de sua produção. Com base nos estudos de Martins (2007), Dantas et al. (2011) e Dias et al. (2011), observa-se que é insatisfatória a divulgação dos resultados das pesquisas realizadas na área de Ciências Contábeis. Assim, é preciso repensar o objetivo da pesquisa contábil e novas formas de divulgá-la, fugindo das formas tradicionais pautadas pela linguagem formal e quase incompreensível pelos "não iniciados" (Ganz, Lima \& Haveroth, 2019).

Destarte, o panorama já abordado, o presente estudo possui como problema central o questionamento de como tem sido divulgado o conhecimento científico gerado pelas teses defendidas nos programas de pós-graduação stricto sensu em Ciências Contábeis no Brasil?

Portanto, este estudo traz como novo, a finalidade de identificar em que patamar está a produção científica proveniente dos programas de pós-graduação nos cursos de Doutorado, tendo como objetivo analisar a evolução da divulgação do conhecimento científico gerado nas teses em Ciências Contábeis no Brasil defendidas nos programas de pós-graduação stricto sensu, durante os anos de 2009 a 2018.

A justificativa deste trabalho é dada por este identificar se o conhecimento produzido nos programas de doutorado está sendo divulgado para a comunidade acadêmica e sociedade em geral, uma vez que a função dos programas de pós-graduação é o desenvolvimento de novos conhecimentos por meio de pesquisas visando o desenvolvimento da sociedade. Demonstrar a contribuição científica das teses para a academia e a sociedade como um todo é primordial, uma vez que todo conhecimento gerado nas universidades, caso não seja divulgado, torna-se obsoleto (Miranda et al., 2013; Paletta, Silva \& Santos, 2014; Pessoni, 2016; Queiroz \& Becker, 2016).

Ao analisar a contribuição dos programas de pós-graduação é possível demonstrar que a pesquisa pode construir novos saberes, verificar a veracidade sobre determinados fatos, averiguar soluções para a resolução de problemas de maneira a contribuir para o crescimento de várias ciências, assim como para o desenvolvimento da sociedade, difundindo o conhecimento (Paletta et al., 2014; Pessoni, 2016; Queiroz \& Becker, 2016). 
Fabre e Bonfante (2017) discutem que, apesar da Ciência Contábil ainda ser um sistema educacional relativamente novo, vem se desenvolvendo nos últimos anos, e que uma forma de demonstrar esse desenvolvimento são as produções acadêmicas que tem contribuído para a evolução dessa ciência. Desta maneira, este estudo servirá para que tanto as organizações quanto os programas de pós-graduação aperfeiçoem ou desenvolvam mecanismos de divulgação que visem levar o conhecimento científico a outras esferas da sociedade, além da academia.

\section{REFERENCIAL TEÓRICO}

A pós-graduação no Brasil teve início na década de 1930, quando surgiu a proposta do Estatuto das Universidades Brasileiras, por intermédio de Francisco Campos, que propôs a implantação de uma pós-graduação a partir dos moldes europeus, sendo implementado na Universidade do Rio de Janeiro - URJ, na Faculdade Nacional de Filosofia - FNFI e na USP (Fávero, 2006).

Destaca-se a influência do modelo francês (sobretudo na Universidade Federal de Viçosa - UFV, na URJ e no Instituto Tecnológico de Aeronáutica - ITA) exercendo influência na institucionalização da pós-graduação, tal como expressa o conteúdo do Parecer do Ministério da Educação n. 977/65, como na constituição/criação autônoma das universidades brasileiras, que se serviu de intelectuais estrangeiros para implantar ou consolidar cursos de graduação e pósgraduação (Almeida \& Maciel 2005; Fávero, 2006; Santos \& Azevedo, 2009).

De maneira geral, a pós-graduação no Brasil foi marcada pela influência externa, incluindo o modelo norte-americano, como por exemplo, o escalonamento que diz que não é preciso a conclusão de um nível para ingresso no outro, uma fase inicial de aulas e um exame geral que verifique a qualidade do candidato - o que seria a qualificação - e a segunda fase a investigação em si - pesquisa, tese e defesa (Alves \& Oliveira, 2014).

Cunha, Cornacchione e Martins (2008) afirmam que, apesar da pós-graduação tornar-se cada vez maior, não é possível observar tal fato na área de Ciências Contábeis, uma vez que até 2008, o único programa em nível de doutorado era o da USP. O programa ofertou a pósgraduação em nível de mestrado até 1977, quando, após um longo processo de convencimento junto ao reitor da instituição, formou-se a primeira turma de doutorado, que viria a titular em 1985, um total de três doutores. O objetivo era a formação de pesquisadores e novos docentes (Peleias et al., 2007).

Paralelo à USP, a Fundação Getúlio Vargas - FGV criou o programa de mestrado, transferido em 1991 para a Universidade Estadual do Rio de Janeiro - UERJ. Após a década de 70, não se observa a criação de novos cursos de mestrado. Em 1996, a Lei 9.394 regulamentou que, pelo menos, $1 / 3$ do corpo docente das universidades deveria ser composto por mestres, com dedicação exclusiva à pesquisa e à docência, fato que poderia servir como motivador para a oferta de mais cursos de mestrado, especialmente em diferentes regiões do Brasil (Peleias et al., 2007).

A partir de 2008 se observa novos cursos de doutorado sendo recomendados pela Capes, como o da Fundação Instituto Capixaba de Pesquisa em Contabilidade Economia e Finanças Fucape, da Universidade de Blumenau - FURB e da FEARP USP/Ribeirão Preto (USP/RP). Dados da Capes (2020) apontam que existem 29 cursos de mestrado acadêmico, 7 mestrados profissionais, 16 doutorados acadêmico e 2 doutorados profissionais. Observa-se dessa forma que a oferta de cursos cresceu significativamente ao longo dos anos. O cenário atual pode ser visualizado na Tabela 1. 
Tabela 1

Programas de Pós-Graduação em Ciências Contábeis no Brasil na data de 05/01/2020

\begin{tabular}{|c|c|c|c|c|c|c|c|}
\hline \multirow{2}{*}{ REGIÃO } & \multirow{2}{*}{$\mathbf{U F}$} & \multirow{2}{*}{ PROGRAMA } & \multirow{2}{*}{ SIGLA IES } & \multicolumn{4}{|c|}{ NOTA DO CURSO } \\
\hline & & & & ME & DO & MP & DP \\
\hline \multirow{4}{*}{$\begin{array}{l}\text { Centro- } \\
\text { Oeste }\end{array}$} & $\mathrm{DF}$ & Ciências Contábeis & UnB & 4 & 4 & & \\
\hline & $\mathrm{DF}$ & $\begin{array}{c}\text { Contabilidade - } \\
\text { UnB/UFPB/UFRN }\end{array}$ & UnB/UFPB/UFRN & 5 & 5 & & \\
\hline & $\mathrm{GO}$ & Ciências Contábeis & UFG & 3 & & & \\
\hline & MS & Ciências Contábeis & UFMS & 3 & & & \\
\hline \multirow{8}{*}{ Nordeste } & $\mathrm{BA}$ & Contabilidade & UFBA & 3 & & & \\
\hline & $\mathrm{CE}$ & $\begin{array}{l}\text { Administração e } \\
\text { Controladoria }\end{array}$ & UFC & 4 & 4 & & \\
\hline & $\mathrm{CE}$ & $\begin{array}{l}\text { Administração e } \\
\text { Controladoria }\end{array}$ & UFC & & & 4 & \\
\hline & MA & $\begin{array}{l}\text { Contabilidade e } \\
\text { Administração }\end{array}$ & FUCAPE & 3 & & & \\
\hline & $\mathrm{PB}$ & Ciências Contábeis & UFPB & 4 & 4 & & \\
\hline & $\mathrm{PE}$ & Ciências Contábeis & UFPE & 4 & 4 & & \\
\hline & $\mathrm{PE}$ & Controladoria & UFRPE & 3 & & & \\
\hline & $\mathrm{RN}$ & Ciências Contábeis & UFRN & 3 & & & \\
\hline \multirow{15}{*}{ Sudeste } & $\mathrm{ES}$ & $\begin{array}{c}\text { Administração e } \\
\text { Ciências Contábeis }\end{array}$ & FUCAPE & 5 & 5 & & \\
\hline & $\mathrm{ES}$ & Ciências Contábeis & FUCAPE & & & 5 & 5 \\
\hline & $\mathrm{ES}$ & Ciências Contábeis & UFES & 4 & 4 & & \\
\hline & MG & Ciências Contábeis & UFU & 4 & 4 & & \\
\hline & MG & $\begin{array}{l}\text { Controladoria e } \\
\text { Contabilidade }\end{array}$ & UFMG & 4 & 4 & & \\
\hline & $\mathrm{RJ}$ & Ciências Contábeis & UFRJ & 5 & 5 & & \\
\hline & $\mathrm{RJ}$ & Ciências Contábeis & FUCAPE & & & 3 & \\
\hline & RJ & Ciências Contábeis & UERJ & 3 & & & \\
\hline & RJ & $\begin{array}{l}\text { Controladoria e } \\
\text { Gestão Pública }\end{array}$ & UERJ & & & A & \\
\hline & SP & Ciências Contábeis & UNIFECAP & 4 & & & \\
\hline & SP & $\begin{array}{c}\text { Ciências Contábeis } \\
\text { e Atuariais }\end{array}$ & PUC & & & 3 & \\
\hline & SP & $\begin{array}{l}\text { Controladoria e } \\
\text { Contabilidade }\end{array}$ & FEA USP & 6 & 6 & & \\
\hline & SP & $\begin{array}{l}\text { Controladoria e } \\
\text { Contabilidade }\end{array}$ & FEARP USP & 5 & 5 & & \\
\hline & SP & $\begin{array}{c}\text { Controladoria e } \\
\text { Finanças }\end{array}$ & FIPECAFI & & & 3 & \\
\hline & SP & $\begin{array}{c}\text { Controladoria e } \\
\text { Finanças } \\
\text { Empresariais }\end{array}$ & UPM & & & 4 & 4 \\
\hline Sul & PR & Ciências Contábeis & UEM & 3 & & & \\
\hline
\end{tabular}




\begin{tabular}{|c|c|c|c|}
\hline PR & Contabilidade & UFPR & 5 \\
\hline PR & Contabilidade & UNIOESTE & 3 \\
\hline RS & Ciências Contábeis & UNISINOS & 5 \\
\hline RS & $\begin{array}{l}\text { Controladoria e } \\
\text { Contabilidade }\end{array}$ & UFRGS & 3 \\
\hline RS & Contabilidade & FURG & 3 \\
\hline $\mathrm{SC}$ & Ciências Contábeis & FURB & 5 \\
\hline $\mathrm{SC}$ & $\begin{array}{c}\text { Ciências Contábeis } \\
\text { e Administração }\end{array}$ & UNOCHAPECÓ & 3 \\
\hline $\mathrm{SC}$ & Contabilidade & UFSC & 5 \\
\hline
\end{tabular}

Legenda: ME: Mestrado Acadêmico; DO: Doutorado Acadêmico; MP: Mestrado Profissional; DP: Doutorado Profissional.

Fonte: Capes (2020).

Segundo dados da FEA USP, o programa de pós-graduação da instituição, desde sua abertura, já titulou mais de 580 mestres e 340 doutores, sendo que os egressos se encontram em "cargos de destaque em diversas áreas, nas esferas pública e privada, acadêmica e empresarial, desde ministérios, presidências de órgãos reguladores, presidências e conselhos administrativos de grandes empresas multinacionais e nacionais" (USP, 2020). A universidade informa que 90\% dos doutores formados pela instituição atualmente são docentes, fato que evidencia que os profissionais capacitados estão atuando junto às universidades e posteriormente formarão novos doutores e mestres para dar continuidade ao ensino e à pesquisa (USP, 2020).

Entretanto, ressalta-se que ainda é um desafio para as Ciências Contábeis no Brasil que os profissionais se dediquem exclusivamente ao ensino e pesquisa, uma vez que a atuação destes no ensino é vista pelos mesmos como complemento salarial em tempo parcial, devido às condições salariais, o que os instiga a atuar concomitantemente como profissional liberal (Silva \& Rodrigues, 2013), fato que engloba também as discussões a respeito das competências pedagógicas que o professor deve possuir, haja visto que sua formação é bacharelado e a literatura aponta falhas na formação docente (Silva, 2020; Araujo, 2017). Neste cenário, a dedicação às pesquisas e, consequentemente, sua divulgação, fica prejudicada e tende a se concentrar nas universidades, que são pautadas no tripé ensino-pesquisa-extensão, e retém grande parte dos professores com titulação de doutores.

Albagli (1996) aponta a diferença entre difusão científica, comunicação científica e divulgação científica, explicando que, enquanto a primeira se refere a qualquer processo de comunicação de informação científica e tecnológica, a segunda implica no direcionamento da informação objetivamente para grupos de especialistas, e a terceira é vista como um processo voltado ao público leigo em geral.

A respeito da divulgação científica no Brasil, houve uma intensificação nas décadas de 20 e 30, quando os meios de comunicação como jornais, revistas, livros e conferências públicas ganharam força, e passaram a ter caráter periódico. Nesse período, apesar de a divulgação científica ainda apresentar um caráter fragmentado, com o acesso não disponível a todos, passou a exercer um papel importante na difusão do conhecimento científico do país (Massarani \& Moreira, 2003).

Para Mansur et al (2021, p. 1) “a divulgação científica, enquanto campo de conhecimento e estratégia de ação, vem ganhando importância crescente no mundo". Para os autores, alguns fatores impulsionam tal crescimento, entre eles, uma resposta da ciência aos movimentos anticiência, e necessidade de desvelar interesses políticos e econômicos que envolvem os questionamentos quanto às evidências científicas. 
Segundo Mueller (2002), o processo de popularização do conhecimento científico possui dificuldades visíveis, e uma delas está em reduzir conceitos complexos, que exigem um domínio de conhecimento ou uma linguagem especializada, a uma linguagem compreensível para a população leiga, ou seja, o processo de adaptação de um texto científico para meios de comunicação popular.

\section{PROCEDIMENTOS METODOLÓGICOS}

O presente estudo possui abordagem qualitativa de caráter descritivo, a partir de pesquisa bibliográfica e documental. Em acesso à Plataforma Sucupira foram coletadas as informações referentes às defesas de tese ocorridas no âmbito dos programas de pós-graduação stricto sensu em Ciências Contábeis no Brasil, entre os anos de 2009 e 2018. Justifica-se o período tendo em vista que o estudo, realizado em 2021, busca capturar a divulgação de tais pesquisas, o que pode levar mais de um ano após sua finalização. Desta maneira, a pesquisa contemplou apenas os doutorados acadêmicos (Tabela 2), uma vez que os programas profissionais são recentes e não formaram profissionais até a data do recorte temporal.

Tabela 2

Cursos de Doutorado em Contabilidade no Brasil que tiveram defesas entre 2009 e 2018

\begin{tabular}{|c|c|c|c|c|}
\hline Região & IES & $\begin{array}{l}\text { Criação } \\
\text { do } \\
\text { Programa }\end{array}$ & $\begin{array}{c}\text { Ano de } \\
\text { atualização } \\
\text { do } \\
\text { Regimento }\end{array}$ & $\begin{array}{c}\text { O que diz o regimento quanto à } \\
\text { divulgação da tese? }\end{array}$ \\
\hline Centro-Oeste & UnB & 2014 & 2019 & $\begin{array}{c}1 \text { artigo publicado ou aceito com } \\
\text { coautoria do orientador }\end{array}$ \\
\hline Nordeste & UFPB & 2015 & 2019 & Sem regras \\
\hline Nordeste/Centro-Oeste & UnB/UFPB/UFRN & 2008 & $0^{*}$ & $\begin{array}{c}1 \text { artigo publicado ou aceito com } \\
\text { coautoria do orientador }\end{array}$ \\
\hline \multirow{5}{*}{ Sudeste } & FEA USP & 1978 & 2017 & Sem Regras \\
\hline & FUCAPE & 2009 & 2019 & Sem Regras \\
\hline & FEARP USP & 2013 & 2013 & $\begin{array}{c}\text { Artigo publicado ou aceito com coautoria } \\
\text { do orientador em periódico de impacto } \\
\text { social }\end{array}$ \\
\hline & UFU & 2016 & 2017 & $\begin{array}{l}3 \text { artigos submetidos, sendo } 1 \text { resultado } \\
\text { da tese de Qualis no mínimo B2 }\end{array}$ \\
\hline & UFRJ & 2014 & 2019 & $\begin{array}{c}1 \text { artigo publicado em periódico de } \\
\text { Qualis no mínimo B1 }\end{array}$ \\
\hline \multirow{4}{*}{ Sul } & FURB & 2008 & 2019 & $\begin{array}{l}2 \text { artigos aceitos ou publicados em } \\
\text { periódico de Qualis no mínimo B2 }\end{array}$ \\
\hline & UNISINOS & 2013 & 2017 & $\begin{array}{l}2 \text { artigos resultados da tese submetidos } \\
\text { com coautoria do orientador em } \\
\text { periódico de Qualis no mínimo B1 }\end{array}$ \\
\hline & UFSC & 2013 & 2015 & Comprovação de publicação \\
\hline & UFPR & 2014 & $0^{*}$ & $\begin{array}{l}1 \text { artigo aceito com coautoria do } \\
\text { orientador ou membro do programa em } \\
\text { periódico de Qualis no mínimo B2 }\end{array}$ \\
\hline
\end{tabular}

*Dado não localizado.

Fonte: Dados da pesquisa (2021)

A pesquisa documental, segundo Beuren (2009), consiste em analisar materiais ainda não tratados analiticamente, como o caso dos currículos lattes, que irão compor o material principal na coleta dos dados, referente às produções acadêmicas dos doutores, com a finalidade de demonstrar a propagação do conhecimento gerado, para a academia e sociedade. O currículo 
lattes é um banco de dados adotado em todo o Brasil onde registra-se as atividades acadêmicas de estudantes, pesquisadores e professores.

Estabelecida a amostra da pesquisa, ocorreu a coleta dos dados, a qual iniciou com o download dos currículos lattes entre os dias 11 e 15 de janeiro de 2021, para que assim fossem coletados os dados referentes às informações das produções dos doutores que compõem a amostra. As seguintes informações foram tabuladas: publicações em periódicos, livros, anais e apresentações em congressos, projetos de pesquisas e orientações, com a finalidade de realizar a triangulação desses dados com a tese defendida, para tanto utilizou-se dos seguintes critérios: títulos iguais ou semelhantes ao da tese ou trabalhos que abordavam a mesma temática utilizada na tese, assim como as palavras-chave. Com esses dados foi possível estabelecer um panorama sobre a propagação das teses, seus meios e nível de divulgação à luz do estrato Qualis. Foram analisados manualmente 348 currículos das 350 defesas, uma vez que dois doutores não tiveram seus currículos localizados na plataforma.

Como metodologia de análise e tratamento dos dados, utilizou-se a análise de conteúdo (Bardin, 2009), que permite a criação de categorizações e codificações sobre os temas apresentados nas teses (Figura 1).

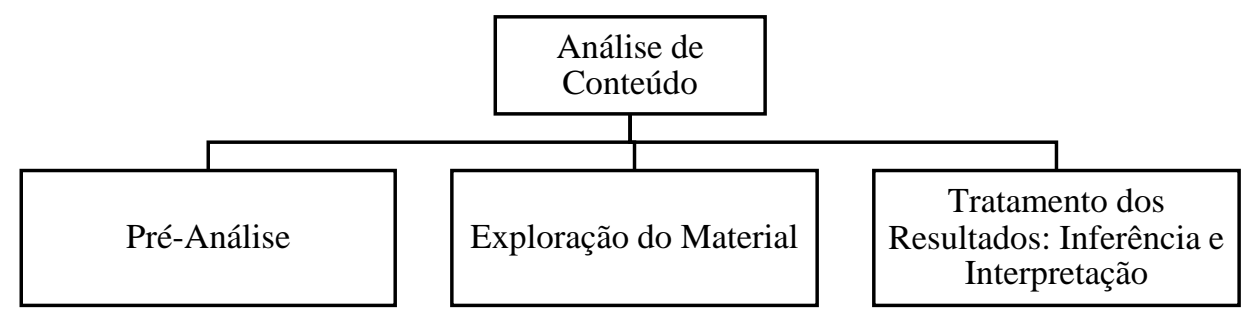

Figura 1. Análise de conteúdo

Fonte: Adaptado de Bardin (2009).

Bardin (2009) conceitua análise de conteúdo como o conjunto de técnicas de análise das comunicações, que visa obter a descrição do conteúdo de mensagens, por meio da utilização de objetivos e procedimentos sistemáticos, que permitem a inferência de conhecimentos relacionados às condições de produção variáveis das mensagens. Portanto, a escolha do uso da análise de conteúdo durante a verificação dos currículos, com a finalidade de obter as informações sobre os produtos que foram fruto das teses, fez-se necessário para se obter os dados fidedignos, com vista de alcançar o objetivo geral da pesquisa.

\section{RESULTADOS E DISCUSSÃO}

Para essa análise foram selecionadas as produções dos doutores desde o ingresso ao programa de pós-graduação até o período em que os currículos foram baixados (janeiro de 2021). Desta maneira, apesar de o recorte temporal ser de 2009 a 2018, as amostras são compostas por todas as produções contidas nos currículos lattes de cada doutor, em que foi possível constatar a existência de produções relacionadas às teses desde 2006 a 2020, pois considerou-se anos anteriores e posteriores às defesas.

\subsection{Panorama dos Programas}

Os dados apresentados direcionam a contribuição referente a 348 currículos e 350 defesas em nível de doutorado, levando em consideração a região do país e a instituição de ensino no período determinado no estudo. Em relação ao panorama regional, observou-se que as universidades situadas na região Sudeste, que abriga cinco instituições, são responsáveis pelos melhores resultados em todas as categorias analisadas. Isso pode estar relacionado ao fato de a 
Universidade de São Paulo (USP) estar localizada nessa região e possuir o curso mais antigo do país, além de ter titulado mais de 340 doutores. Os menores resultados observados concentramse na região Nordeste do país.

Entre os doutores que compõem a amostra, participam e/ou participaram de 1.181 projetos de pesquisas, 11.161 bancas de defesa, sejam elas de mestrado, doutorado, qualificações ou trabalhos de conclusão de curso (Tabela 3). Ressalta-se que ao elaborar um projeto de pesquisa, os doutores contribuem para que novos conhecimentos sejam gerados, assim como participar de uma banca faz com que atuem diretamente na formação de outros profissionais, desde os níveis de graduação até a qualificação de novos doutores. Destaca-se, por exemplo, a contribuição dos doutores da FEA USP e FURB, que possuem 68,0\% dos projetos de pesquisas observados e cerca de 70,0\% das participações em bancas.

Tabela 3

Resultados de participação de doutores em projetos de pesquisa, bancas, congressos e orientações por instituição de ensino

\begin{tabular}{ccccc} 
Universidade & Projetos de Pesquisa & Bancas & Apresentação em congressos & Orientações \\
& & & & \\
\hline FUCAPE & 10,0 & 296,0 & 71,0 & 226,0 \\
FURB & 224,0 & $1.760,0$ & 504,0 & $1.589,0$ \\
UnB/UFPB/UFRN & 207,0 & $1.951,0$ & 302,0 & $1.625,0$ \\
UFPB & 3,0 & 21,0 & 12,0 & 20,0 \\
UFPR & 26,0 & 187,0 & 59,0 & 217,0 \\
UFRJ & 14,0 & 81,0 & 26,0 & 88,0 \\
UFSC & 22,0 & 87,0 & 29,0 & 135,0 \\
UFU & 6,0 & 32,0 & 12,0 & 68,0 \\
UnB & 18,0 & 67,0 & 7,0 & 85,0 \\
UNISINOS & 38,0 & 394,0 & 30,0 & 275,0 \\
FEARP USP & 32,0 & 238,0 & 133,0 & 123,0 \\
FEA USP & 581,0 & $6.047,0$ & $1.461,0$ & $4.755,0$ \\
\hline Soma & $1.181,0$ & $11.161,0$ & $2.646,0$ & $9.206,0$ \\
Média & 98,4 & 930,1 & 220,5 & 767,2 \\
Desvio padrão & 170,2 & $1.743,7$ & 418,4 & $1.379,7$ \\
\hline
\end{tabular}

Fonte: Dados da pesquisa (2021).

De acordo com os estudos de Martins e Monte (2009), 30,0\% dos doutores do programa multi-institucional (UnB/UFPB/UFRN) mencionam em seus currículos que participam ou participaram de algum grupo de pesquisa. Esses resultados são inferiores ao encontrado neste estudo, em que $73,0 \%$ dos doutores, considerando todos os programas analisados, mencionaram a participação em grupos de pesquisa em seus currículos. Em relação ao programa multiinstitucional (UnB/UFPB/UFRN), apenas $25,0 \%$ de todos os doutores estudados da instituição não mencionam em seus currículos a participação em projetos, ou seja, 75,0\% declaram estar inseridos em projetos de pesquisa. Esses resultados são superiores aos encontrados nos estudos de Martins e Monte (2009), nos quais os autores enfatizam, ainda, que o número de participações em projetos aumenta em decorrência de ingresso no programa de mestrado, alcançando resultados superiores após sua conclusão.

Em relação às orientações, no período estudado, os doutores orientaram 9.206 discentes, levando em consideração estudantes de mestrado, doutorado, especialização, trabalhos de 
conclusão de curso, iniciação científica e pós-doutoramento. Deste universo amostral, apenas $18,0 \%$ dos doutores não informaram orientações em seus currículos. A qualidade da orientação depende de muitos fatores, como, por exemplo, muitas orientações simultâneas que exigem mais tempo e atenção aos alunos, assim como o comprometimento dos alunos quanto ao entendimento da metodologia e cumprimento de prazos (Silva et al., 2019).

Levando em consideração o universo de doutores da amostra, em média cada doutor orientou ou orienta aproximadamente 27 alunos ao longo de 10 anos, ou seja, cerca de 3 orientados por ano. O maior número de estudantes orientado e registrado pelos doutores correspondeu a 181 discentes, observado no currículo lattes do Dr. Sady Mazzioni da FURB, titulado em 2015. E, desconsiderando os 62 doutores que não orientam nenhum aluno ou não mencionaram a orientação em seus currículos, o mínimo encontrado foi 1 discente nos currículos de 6 doutores, sendo da USP, 2 titulados em 2018, 1 em 2016 e 1 em 2011 e 2 do programa multi-institucional da UnB/UFPB/UFRN, titulados em 2014 e 2017, respectivamente.

No que tange aos trabalhos publicados em congressos e anais de eventos, os doutores declararam possuir 2.646 trabalhos em congressos e eventos acadêmicos e publicar 6.687 trabalhos completos em anais (Tabela 4). Dos trabalhos publicados, 6,17\% (413) tem alguma relação com a tese defendida para obtenção do título de doutor. Nas pesquisas de Oliveira et al. (2007), ao estudarem 85 pesquisadores das áreas de administração e contabilidade com bolsas de produtividade concedidas pelo CNPq, observaram que, em média, os doutores publicaram 34 artigos em anais de eventos, sendo que 25 destes eram eventos internacionais. Neste estudo, a média por doutor é de 19 artigos em anais de congressos, sem levar em conta a natureza do evento, se nacional ou internacional.

Tabela 4

Publicações geradas a partir das teses dos doutores

\begin{tabular}{cccccccccc}
\hline & \multicolumn{2}{c}{$\begin{array}{c}\text { Anais de } \\
\text { congresso }\end{array}$} & Periódico & Livro & \multicolumn{2}{c}{$\begin{array}{c}\text { Capítulo de } \\
\text { livro }\end{array}$} & $\begin{array}{c}\text { Total de produtos } \\
\text { gerados a partir } \\
\text { de Tese }\end{array}$ \\
& Total & $\mathbf{1}$ RT & Total & $\mathbf{1}$ RT & Total & 1RT & Total & 1RT & 2RTT \\
\hline FUCAPE & 80,0 & 3,0 & 85,0 & 2,0 & 0,0 & 0,0 & 0,0 & 0,0 & 5,0 \\
FURB & $2.017,0$ & 109,0 & $1.525,0$ & 52,0 & 32,0 & 2,0 & 104,0 & 0,0 & 163,0 \\
UnB/UFPB/UFRN & 692,0 & 58,0 & 907,0 & 56,0 & 45,0 & 2,0 & 96,0 & 2,0 & 118,0 \\
UFPB & 35,0 & 6,0 & 27,0 & 6,0 & 2,0 & 0,0 & 2,0 & 0,0 & 12,0 \\
UFPR & 94,0 & 5,0 & 119,0 & 4,0 & 7,0 & 0,0 & 2,0 & 0,0 & 9,0 \\
UFRJ & 110,0 & 8,0 & 120,0 & 3,0 & 2,0 & 0,0 & 4,0 & 1,0 & 12,0 \\
UFSC & 186,0 & 14,0 & 118,0 & 7,0 & 6,0 & 0,0 & 7,0 & 0,0 & 21,0 \\
UFU & 26,0 & 1,0 & 31,0 & 2,0 & 0,0 & 0,0 & 7,0 & 0,0 & 3,0 \\
UnB & 68,0 & 1,0 & 97,0 & 8,0 & 4,0 & 0,0 & 9,0 & 1,0 & 10,0 \\
UNISINOS & 153,0 & 4,0 & 135,0 & 4,0 & 11,0 & 0,0 & 34,0 & 2,0 & 10,0 \\
FEARP USP & 166,0 & 16,0 & 116,0 & 18,0 & 8,0 & 1,0 & 10,0 & 1,0 & 36,0 \\
FEA USP & $3.060,0$ & 188,0 & $2.188,0$ & 140,0 & 138,0 & 12,0 & 296,0 & 16,0 \\
\hline Soma & 6687,0 & 413,0 & 5468,0 & 302,0 & 255,0 & 17,0 & 571,0 & 23,0 & 356,0 \\
Média & 557,3 & 34,4 & 455,7 & 25,2 & 21,3 & 1,4 & 47,6 & 1,9 & 62,9 \\
Desvio padrão & 967,8 & 58,0 & 709,5 & 40,9 & 39,3 & 3,4 & 86,3 & 4,5 & 105,3 \\
\hline
\end{tabular}

Legenda: ${ }^{1 R T}$ : resultado de teses; ${ }^{2} \mathrm{RTT}$ : resultados totais de publicações geradas a partir de tese.

Fonte: Dados da pesquisa (2021). 
Quanto ao número de artigos publicados em periódicos, foram encontrados 5.468 artigos no período analisado. Dentre esses, 16,5\% (302) são relacionados ao resultado das pesquisas de doutorado e foram publicados em revista com Qualis variando de A1 a C. Em relação às 148 revistas analisadas, destacam-se, com $40 \%$ das publicações, as revistas Universo Contábil (A2), com 20 publicações; Contabilidade \& Finanças (A2), com 16 publicações; Advances In Scientific and Applied Accounting (A2) e Revista Contemporânea de Contabilidade da UFSC (A2), ambas com 15 publicações; Revista de Contabilidade e Organizações (A2), com 11 publicações; Revista de Educação e Pesquisa em Contabilidade - REPEC (B1), com 10 publicações; e com 8 publicações as revistas Brazilian Business Review - BBR (A2), Contabilidade Vista \& Revista (A2) e Journal of Accounting, Management and Governance - JAMG (B1), todas com classificação de acordo com o quadriênio 2013-2016.

Em relação aos livros publicados, dos 255 mencionados, 6,6\% (17) têm relação direta com a tese e, dos 571 capítulos de livros, cerca de 4,0\% (23) estão diretamente relacionados à tese. Apenas $34,0 \%$ dos doutores foram responsáveis por escrever livros na íntegra e 49,0\% com participação em capítulos de livros. De forma geral, 45,8\% de todas as produções entre livros e capítulos de livros possuem relação com as teses publicadas pelos doutores em estudo.

Considerando todos os trabalhos relacionados à tese, somente 3,0\% são capítulos de livros e $2,2 \%$ são livros. Do total de trabalhos relacionados à tese, as publicações em anais de eventos correspondem a 54,7\% e os artigos científicos, 40,0\%. O maior número de publicações em anais de congresso está relacionado aos eventos realizados (nacionais e internacionais) na área de contabilidade. De acordo com Oliveira et al. (2007), o Encontro Nacional de PósGraduação (EnANPAD) é responsável por abrigar um volume expressivo de publicações, diferente dos resultados encontrados neste estudo em que a maioria das publicações (19) ocorreram na International Conference in Accounting. Vendramin et al. (2020), ao analisarem a International Conference in Accounting, observaram que a FEA USP se destaca no número de publicações no evento, chegando a publicar o dobro do total de artigos publicados pela segunda instituição, a Universidade Regional de Blumenau. Das instituições estudadas neste trabalho, apenas a FEA USP encontra-se entre as 10 instituições que mais publicam na International Conference in Accounting, conforme a amostra estudada por Vendramin et al. (2020).

Outros estudos com análises bibliométricas de produção científica apontam que os artigos científicos são os principais produtos gerados a partir de teses, em seguida livros e capítulos de livros são os destinos secundários e, em menor percentual, os trabalhos publicados em anais de eventos (Noronha, 1997; Sacardo \& Hayashi, 2011). Esses resultados diferem dos encontrados neste estudo, em que os anais de congresso são o principal destino das publicações, seguido dos artigos científicos e, em menor proporção para livros e capítulos de livros.

Todavia, neste estudo observou-se, em média, pelo menos uma publicação originada a partir da tese, sejam artigos em periódicos, anais de eventos, livros ou capítulos de livro. Valores semelhantes obtiveram Sacardo e Hayashi (2011), em que cada autor publicou 1,4 artigos. Destaca-se que para a avaliação da Capes junto aos programas de pós-graduação, considera-se docentes com produção boa quando os docentes permanentes dos programas produzem no mínimo 4 artigos no quadriênio (Capes, 2021).

\subsection{Universidades localizadas na região Centro-Oeste e Nordeste (UnB, UFPB, UnB/UFPB/UFRN)}

Os sete doutores que se titularam pela Universidade de Brasília - UnB, no ano de 2018, desenvolveram 18 projetos de pesquisa, correspondentes a $1,5 \%$ da amostra analisada, além de participar de 67 bancas, $0,6 \%$ do total analisado. No que tange às orientações, foram orientados cerca de 85 alunos, equivalente a 1,0\% da amostra, e apresentaram sete trabalhos em eventos 
acadêmicos, representando $1,0 \%$ do total geral, resultados estes não identificados como relacionados às teses.

Os doutores publicaram 68 trabalhos completos em anais de congressos, cerca de $1 \%$ de toda a amostra, 97 artigos em periódicos, cerca de $2 \%$ de todos os artigos estudados. Publicaram também 4 livros não identificados como relacionados às suas respectivas teses e 9 capítulos de livros, ambos $1,5 \%$ do total da amostra. Destaca-se que somente 1,4\% dos trabalhos em anais de congresso e $8,2 \%$ dos artigos em periódicos dos doutores da UnB possuem relação direta com as teses.

Levando em consideração o número de doutores da UnB na pesquisa, a média corresponde a 13 trabalhos em anais de congressos e 14 artigos em periódicos por doutor. Em se tratando dos trabalhos relacionados às teses, $0,2 \%$ dos trabalhos estão publicados em anais de congresso, 2,6\% dos periódicos e 4,3\% dos capítulos de livros são oriundos dos doutores desta instituição.

Os doutores advindos da Universidade Federal da Paraíba - UFPB defenderam 4 teses, todas no ano de 2018 na linha de Informação Contábil para Usuários Externos. Tais doutores mencionaram em seus currículos 3 projetos de pesquisa, que corresponde a $0,25 \%$ da amostra, participação em 21 bancas com $0,2 \%$ do total estudado, orientação de 20 alunos, 0,2\% da amostra e apresentação de 12 trabalhos em eventos acadêmicos correspondente a $0,5 \%$ do total geral não relacionados às teses.

Os doutores titulados pela instituição publicaram 35 trabalhos completos em anais de congressos, $0,5 \%$ da amostra, 27 artigos em revistas, que corresponde a 0,5\% de todos os artigos analisados. Os doutores publicaram 2 livros e 2 capítulos de livros, 0,7\% e 0,3\%, respectivamente, da amostra estudada. Em se tratando dos trabalhos relacionados às teses, 17,0\% estão publicados em anais de eventos e $22 \%$ estão publicados como artigos em periódicos. A média de publicações por doutor da UFPB é de 9 trabalhos em anais de congressos e 7 artigos. Analisando somente os trabalhos que possuem alguma relação com a tese, 1,5\% dos trabalhos estão em anais de congresso e 2,0\% em periódicos científicos.

No programa multi-institucional e inter-regional - UnB, UFPB e UFRN (Universidade Federal do Rio Grande do Norte) os doutores defenderam 64 teses entre os anos de 2010 e 2018, destas 33 correspondem a linha de Contabilidade e Finanças, 19 são da linha de Contabilidade para Tomada de Decisão, 10 da linha de Impactos da Contabilidade para a Sociedade e 2 não informaram a sua linha de pesquisa. Os doutores do programa multi-institucional da UnB, UFPB e UFRN comprovaram em seus currículos a participação em 207 projetos de pesquisa, 1.951 bancas e orientação de 1.625 estudantes, ambos correspondem a 17,0\% da amostra estudada, e corroboram 302 apresentações de trabalhos em eventos, cerca de 10,0\% da amostra. Os dados apontam que os anos de 2012 e 2016 foram mais expressivos em relação ao número de produções científicas dos doutores.

Os doutores desta instituição foram responsáveis por publicar cerca de 692 trabalhos completos em anais de congressos nacionais e internacionais, correspondente a $10,0 \%$ de todos os trabalhos analisados. A média por doutor do programa é de 10 trabalhos, cujos anos de 2011, 2012 e 2016 houve maior número de publicações. Ao analisar a relação destas publicações com as temáticas realizadas na elaboração das teses, $14,0 \%$ correspondem aos trabalhos publicados em anais de congressos.

Em relação a publicação de artigos científicos, observou-se 907 artigos publicados em revistas indexadas, valor que corresponde a 16,6\% da amostra estudada. Ao analisar a relação destes artigos com as teses, estima-se que 18,0\% estão diretamente associadas às temáticas das teses defendidas para obtenção do título de doutor. Para essa instituição, a média de publicação em revista é de 14 artigos por doutor, em que os anos de 2016 e 2012 foram os mais representativos quanto ao número de publicações. 
Os doutores titulados pelo programa multi-institucional publicaram 96 capítulos de livros, destes, $8,0 \%$ possuem relação com a tese, com média de 1 capítulo e meio por doutor. Em relação aos livros publicados, de um total de 45 livros (17,0\% da amostra total), $11,0 \%$ dessas publicações estão diretamente relacionados à tese.

O programa multi-institucional, ao lado do programa da FURB e da FEA USP, foi responsável pelos maiores índices de publicação. Em se tratando da FURB, as defesas foram obtidas entre os anos 2011 a 2018 com média de 5,6 teses defendidas por ano, sendo que no ano de 2015 houve maior pico, com 11 teses defendidas. Em contrapartida, FEA USP obteve defesas entre os anos de 2009 e 2018 com média de 16,5 teses defendidas por ano, sendo o ano de 2016 o maior pico, com 26 teses defendidas. Vale ressaltar que o programa multi-institucional da UnB/UFPB/UFRN foi considerado um avanço por ser precursor na região Nordeste e Norte do país, ao levar o doutorado em ciências contábeis para a região.

\subsection{Universidades localizadas na região Sudeste (FUCAPE, UFRJ, UFU, FEARP USP, FEA USP)}

Os doutores titulados pela instituição em Ciências Contábeis e Administração da FUCAPE defenderam 7 teses ao longo do período de 2013 a 2018, sendo 5 na linha de Finanças e Avaliação de Empresas e 2 na linha de Contabilidade e Gestão Estratégica. Entre 2013 e 2018 os doutores tiveram participação em 10 projetos de pesquisa, o que corresponde a $0,85 \%$ da amostra estudada, 226 orientações, 2,45\% do total analisado, 296 bancas, $2,65 \%$ e 71 apresentações em congressos, correspondente a 3,0\% da amostra.

Os doutores titulados pela FUCAPE publicaram 80 trabalhos em anais de congressos, $1,2 \%$ da amostra e 85 artigos em periódicos, $1,55 \%$ do total observado. O ano de 2017 foi o ano com o maior número de publicações em anais de congressos, ao passo que, em 2014 houve maior publicação em periódicos científicos. Vale ressaltar que apenas 1 doutor publicou 26 trabalhos em anais de congressos e 24 artigos em periódicos. Levando em consideração a média por doutor no programa, em torno de 11 trabalhos foram publicados em anais de congresso e 12 artigos em revista.

Dentre as publicações relacionadas com a tese, $3,7 \%$ dos trabalhos estão publicados em anais e 2,3\% dos artigos em periódicos. Para doutores formados na FUCAPE, analisando apenas publicações relacionadas à tese, $0,73 \%$ correspondem a trabalhos em anais de congresso e $0,66 \%$ em periódicos.

Dentre os 10 doutores titulados pela Universidade Federal do Rio de Janeiro - UFRJ, foram desenvolvidos 14 projetos de pesquisa, correspondente a 1,2\% de todos os projetos levantados na amostra, participação em 81 bancas, $0,7 \%$ do total levantado, orientação de 88 alunos, $1,0 \%$ da amostra e apresentação de 26 trabalhos em eventos acadêmicos, correspondente a 1,0\% do total geral. Analisando somente os trabalhos que têm relação com a tese, $1,94 \%$ dos trabalhos em anais de congresso, $1,0 \%$ dos periódicos e 4,3\% dos capítulos de livros são de doutores formados pela URFJ.

Os doutores do programa publicaram 110 trabalhos completos em anais de congressos, $1,6 \%$ da amostra total, 120 artigos em revistas, cerca de 2,0\% de todos os artigos estudados, 2 livros e 4 capítulos de livros, $0,8 \%$ e $0,7 \%$, respectivamente. Ressalta-se que o programa exige pelo menos 1 artigo publicado em revista de Qualis B1 para titulação, entretanto a média de publicação por doutor é de 11 trabalhos em anais e 12 artigos em periódicos. O maior número de publicações em anais foi observado no ano de 2018 e os artigos em maior proporção no ano de 2017. Relacionados à tese, observa-se 7,3\% dos trabalhos publicados em anais e 2,5\% em artigos de periódicos.

O curso de doutorado do Programa de Pós-Graduação em Ciências Contábeis da Universidade Federal de Uberlândia - UFU teve 4 teses defendidas no ano de 2018, 3 na linha de 
Contabilidade Financeira e 1 na linha de Controladoria. Destaca-se que os discentes defenderam suas teses após dois anos matriculados no curso, tempo mínimo permitido pelo regime interno do programa. Os profissionais relataram em seus currículos o desenvolvimento de 6 projetos de pesquisa, o que corresponde a $0,5 \%$ de toda a amostra, participação em 32 bancas, $0,3 \%$ do total analisado, orientação de 68 discentes, $0,74 \%$ da amostra e apresentação de 12 trabalhos em eventos acadêmicos, $0,45 \%$ do total geral.

Os doutores titulados pela instituição publicaram 26 trabalhos completos em anais de congressos, o que corresponde a $0,4 \%$ de toda a amostra analisada, 31 artigos em periódicos, valor que corresponde a $0,6 \%$ de todos os artigos estudados e 7 capítulos de livros, $1,2 \%$ de toda a amostra estudada. A média de publicação é de 6 trabalhos em anais e 7 artigos em periódicos por doutor. Somente 3,8\% dos trabalhos em anais e 6,4\% dos artigos em periódicos possuem relação com a tese. Observando apenas os trabalhos que possuem alguma relação com a tese de doutores formados pela UFU, $0,24 \%$ destes estão publicados em anais de congresso, e $0,66 \%$ estão publicados em periódicos.

O programa de Pós-Graduação em Controladoria e Contabilidade da Universidade de São Paulo de Ribeirão Preto - FEARP USP teve 18 defendidas no período de 2016 a 2018, destas 12 na linha de Contabilidade Financeira e Finanças, 2 na antiga linha de Controladoria, uma na linha de Instituições e Eficiência das Organizações e 3 não especificaram a linha de pesquisa. Os doutores mencionaram em seus currículos o desenvolvimento de 32 projetos de pesquisa, 2,7\% da amostra estudada, participação em 238 bancas, 2,1\% do total analisado, orientação de 123 alunos, $1,3 \%$ da amostra e apresentação de 133 trabalhos em eventos acadêmicos, cerca de 5\% do total geral.

Os doutores da FEARP USP foram responsáveis por publicarem 166 trabalhos completos em anais de congressos, 2,5\% de toda a amostra, 116 artigos em revistas, cerca de 2,0\% de todos os artigos levantados. Publicaram também, 8 livros e 9 capítulos de livros, 3,0\% e 1,6\%, respectivamente, de todo o total estudado. Apenas 9,6\% dos trabalhos em anais e 15,5\% dos artigos em periódicos possuem relação com a tese. Para receber título de doutor, conforme o regimento interno, é necessário publicar ou ter o aceite de pelo menos um artigo em coautoria com o orientador em uma revista com impacto social. A média de publicação para o programa é de 9 trabalhos em anais de congresso e 6 artigos por doutor.

Em relação aos trabalhos que possuem alguma relação com a tese, de doutores formados na FEARP USP, 3,8\% dos trabalhos foram publicados em anais de congresso, 6,0\% em periódicos, $6,0 \%$ em livros e 4,3\% em capítulos de livros.

O Programa de Pós-Graduação em Controladoria e Contabilidade da FEA USP é o mais antigo programa de pós-graduação em Ciências Contábeis do Brasil. Dentre os doutores do programa foram avaliados 164 currículos, e 165 defesas feitas no programa para o período analisado, destes, 1 currículo não foi localizado na plataforma lattes. Das teses defendidas, 40 correspondem à linha Contabilidade para Usuários Externos, 45 da linha Educação e Pesquisa em Contabilidade, 46 da linha Controladoria e Contabilidade Gerencial e 33 da linha de Mercados Financeiro, de Crédito e de Capitais.

Ao longo do recorte temporal, os doutores participaram de 581 projetos de pesquisas, cerca de $50,0 \%$ de todos os projetos analisados, orientaram 4.755 alunos e participaram de 6.047 bancas. Os profissionais mencionaram a participação em 1.461 eventos acadêmicos nos quais apresentaram trabalhos, tal valor corresponde a mais de 55,0\% da amostra geral (Figura 2). Vale ressaltar que a produção caiu ao longo do tempo, independente da categoria, sendo 2017 e 2018 os anos com menores índices. 


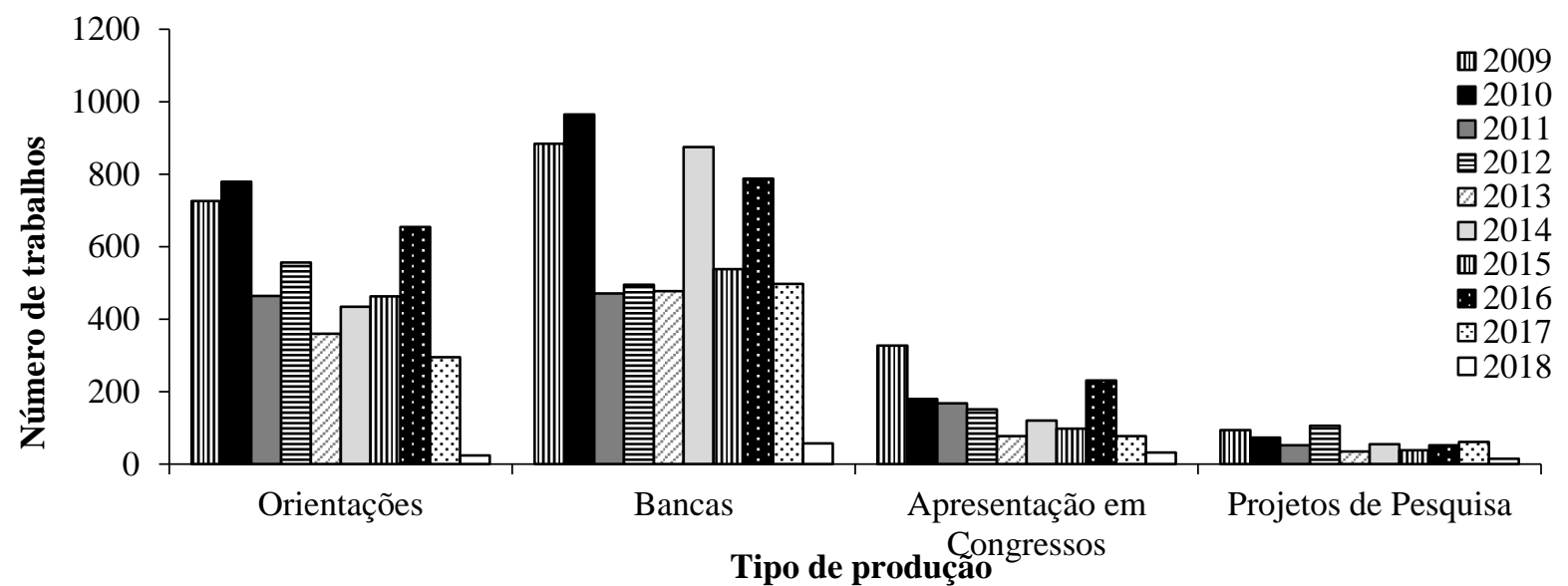

Figura 2. Produções realizadas pelos doutores da FEA USP titulados entre os anos de 2009 e 2018.

Fonte: Dados da pesquisa (2021).

Foram publicados 2.188 artigos em periódicos, cerca de 40,0\% das publicações em revistas de toda a amostra observada. De todos os artigos publicados (2.188) em revistas pelos doutores titulados pela FEA USP, 6,4\% (140) são relacionados à tese, no entanto, se levarmos em consideração que a FEA USP teve 165 defesas e 140 artigos publicados relacionados à tese, verifica-se um índice alto, de $84,8 \%$. Destaca-se que a FEA USP não possui em seu regimento um regulamento que obrigue os discentes do curso de doutorado a realizar publicações como subproduto das teses, seja em congressos ou periódicos, entretanto a média da instituição é de 13 artigos por doutor.

Os profissionais formados pela instituição publicaram 138 livros, valor que corresponde a $54,0 \%$ das publicações gerais nesta categoria. Apenas 8,7\% dos livros publicados possuem relação com a tese. Ao analisar os doutores da FEA USP até o ano de 2005, Borba et al. (2007) afirmam que os 114 profissionais estudados até aquela data publicaram 272 livros ao longo de 27 anos, uma média de aproximadamente três livros por doutor e 10 por ano. A média observada nos 10 anos deste estudo é de um livro por doutor, ou seja, 14 livros por ano.

Foram publicados 296 capítulos de livros, cerca de 50,0\% do total geral analisado. No que tange aos capítulos de livro, somente 5,4\% possuem relação com a tese. Borba et al. (2007) afirmam que os 114 profissionais estudados até 2005 publicaram 169 capítulos de livros ao longo de 27 anos do programa, em média sete capítulos por ano. Para este estudo, a média corresponde a 30 capítulos por ano no recorte temporal definido entre 2010-2018. Logo, apesar da média por doutor diminuir, o número de capítulos, assim como o de livros, aumentou, vale ressaltar que o recorte temporal de Borba et al. (2007) é maior e o número de doutores menor.

Em relação aos trabalhos completos publicados em anais de congresso, os doutores publicaram 3.060 artigos, o que corresponde a 45,0\% do total da amostra e destes, somente $6,14 \%$ possuem relação com a tese.

No que tange à produção de maneira geral, a FEA USP responde por $44,0 \%$ das publicações. Resultados semelhantes foram encontrados por Costa e Lustosa (2009), que observaram que os doutores do programa de Controladoria e Contabilidade da instituição eram responsáveis por 50,0\% das publicações analisadas entre 2000 e 2009, considerando a Contabilidade Gerencial. Ressalta-se que a universidade ainda é responsável em todas as categorias analisadas pelos maiores índices, mesmo sem possuir regras que torne obrigatória a publicação entre seus discentes. 


\subsection{Universidades localizadas na região Sul (FURB, UFPR, UFSC, Unisinos)}

Os doutores titulados pela Fundação Universitária de Blumenau - FURB desenvolveram 224 projetos de pesquisa relatados em seus currículos lattes, correspondente a 19,0\% da amostra estudada, participação em 1.760 bancas, $15,0 \%$ do total analisado, orientação de 1.589 alunos, $17,0 \%$ da amostra e apresentação de 504 trabalhos em eventos acadêmicos, 19,0\% do total geral. Os doutores publicaram 2.017 trabalhos completos em anais de congressos, cerca de 30,0\% da amostra total. Em se tratando de trabalhos publicados em anais de evento, 5,4\% possuem relação com a tese. A média de trabalhos publicados em anais para a instituição é de 46 por doutor, maior média entre as instituições estudadas.

Foram publicados 1.525 artigos em revistas, valor que corresponde a $28,0 \%$ de todos os artigos da amostra. Dos artigos em revista, apenas 3,4\% possuem relação com a tese. Ressalta-se que a instituição possui o regulamento direcionado à publicação ou aceite de 2 artigos em periódicos de Qualis no mínimo B1. A média de publicação de artigos é de 35 por doutor, maior média entre as instituições. Nos anos de 2015, 2014 e 2011 observa-se maior número de publicações.

Os doutores titulados pela instituição publicaram 32 livros, $12,5 \%$ da amostra. Dos livros publicados, somente $6,2 \%$ estão diretamente relacionados às teses. Em relação às publicações em capítulos de livros, foram observados 104 capítulos publicados pelos doutores titulados na FURB, correspondente a $18,0 \%$ dos trabalhos analisados na amostra, porém nem um desses trabalhos está relacionado à tese.

No ano de 2015 observa-se maior número de publicações em anais de eventos científicos, possivelmente relacionados ao maior número de eventos ocorridos neste ano. Considerando apenas os trabalhos que possuem alguma relação com a tese, $26,0 \%$ dos trabalhos em anais de congresso, 17,0\% dos periódicos e 11,0\% dos livros são de doutores da FURB.

Dentre as defesas dos doutores formados pela Universidade Federal do Paraná - UFPR, 10 teses foram defendidas entre os anos 2017 e 2018, 5 são da linha de Contabilidade e Controle Gerencial e 5 da linha de Contabilidade Financeira e Finanças. Os doutores desenvolveram 26 projetos de pesquisa, 2,2\% da amostra estudada, com participação em 187 bancas, 1,7\% do total analisado, orientação de 217 alunos, 2,4\% da amostra e apresentação de 59 trabalhos em eventos acadêmicos, $2,2 \%$ do total geral.

Foram publicados 94 trabalhos completos em anais de congressos, 1,4\% de toda a amostra, 119 artigos em revistas, valor que corresponde a 2,7\% de todos os artigos estudados. Os doutores publicaram sete livros, correspondente a $2,7 \%$ da amostra e dois capítulos de livros, $0,3 \%$ do total amostrado. Relacionados às teses, $5,3 \%$ dos trabalhos foram publicados em anais de eventos e 3,3\% dos artigos em periódicos. O programa exige para titulação um artigo aceito para publicação em coautoria com o orientador ou qualquer docente do programa. A média de publicação é de 9 trabalhos em anais e 12 artigos em periódico, por doutor.

Das publicações relacionadas às teses de doutores formados pela UFPR, 1,2\% correspondem aos trabalhos publicados em anais de congresso e 1,3\% estão publicados em periódicos científicos.

O curso de doutorado do programa de Pós-Graduação em contabilidade da Universidade Federal de Santa Catarina - UFSC teve sete defesas realizadas entre 2016 e 2018, 5 são da linha de Controle de Gestão e Avaliação de Desempenho e dois da linha de Contabilidade Financeira e Pesquisa em Contabilidade. Os profissionais registraram em seus currículos o desenvolvimento de 22 projetos de pesquisa, cerca de $2,0 \%$ da amostra estudada, participação em 87 bancas, $0,8 \%$ do total analisado, orientação de 135 alunos, 1,5\% da amostra analisada e apresentação de 29 trabalhos em eventos, $1,0 \%$ do total geral.

Os doutores publicaram 186 trabalhos completos em anais de congressos, cerca de 3,0\% de toda a amostra, 118 artigos em revistas, cerca de 2,0\% de todos os artigos analisados. 
Publicaram também 6 livros e 7 capítulos de livros, 2,3\% e 1,0\% da amostra, respectivamente. Apenas 7,5\% dos trabalhos publicados em anais e 6,0\% dos artigos são relacionados à tese. $\mathrm{O}$ programa exige comprovante de publicação em periódico, para titulação, entretanto, não especifica quantidade e tampouco o Qualis da revista. A média de publicação para o programa é de 27 trabalhos em anais e 17 artigos por doutor.

Dentre os pesquisadores que se titularam na UFSC, apenas os trabalhos que possuem alguma relação com a tese correspondem a 3,4\% dos trabalhos publicados em anais de congresso, e $2,3 \%$ em periódicos.

Os 9 doutores titulados pela Universidade do Vale do Rio dos Sinos - Unisinos, registaram o desenvolvimento de 38 projetos de pesquisa, 3,2\% da amostra estudada, participação em 394 bancas, 3,5\% do total analisado, orientação de 275 estudantes, 3,0\% da amostra e apresentação de 30 trabalhos em eventos acadêmicos, 1,0\% do total.

Os doutores publicaram 153 trabalhos completos em anais de congressos, cerca de 2,0\% de toda a amostra, 135 artigos em periódicos reconhecidos, valor que corresponde a 2,5\% de todos os artigos estudados. Apenas 2,6\% dos trabalhos publicados em anais e 2,9\% dos artigos são relacionados à tese. Em relação aos livros, foram publicados 11 livros, 1,0\% do total da amostra e 34 capítulos de livros, cerca de $6,0 \%$ da amostra. A instituição possui como regulamento para titulação a submissão de 2 artigos resultantes da tese em coautoria com o orientador em revista de Qualis no mínimo B1. A média de publicação é de 17 trabalhos em anais e 15 artigos em revista por doutor.

Considerando apenas os trabalhos que possuem relação com a tese, 1,0\% dos trabalhos em anais de congresso, $1,3 \%$ dos periódicos e $8,7 \%$ capítulos de livros são de doutores que estudaram na Unisinos.

\subsection{Classificação das publicações em periódicos quanto ao conceito Qualis Capes}

O Qualis Periódicos é uma ferramenta implementada pela Capes, cujo propósito é classificar os periódicos por meio de notas que avaliam diversos critérios. Tal classificação é relevante, especialmente, por tornar possível uma métrica quantitativa para mensurar a qualidade dos artigos publicados por pesquisadores. De tempos em tempos, conforme a necessidade, a classificação sofre ajustes, para refletir a realidade das áreas do conhecimento. Assim, o Qualis Periódico não é uma classificação absoluta, está em constante revisão e é utilizado para avaliação dos programas como um indicador científico e até mesmo como política (Frigeri \& Monteiro, 2014; Barata, 2016). Ao escolher um periódico para publicar um artigo científico o autor deve atentar-se, mais que o Qualis, para o público-alvo do artigo, a credibilidade, a rapidez no julgamento e publicação, a circulação que os periódicos têm na comunidade de interesse, como é prestigiada e o fator de impacto, dentre outros fatores.

Dentre as instituições selecionadas, apenas os programas da USP, FUCAPE e UFPB não obrigam seus discentes a publicar os produtos de suas teses em periódicos com alto fator de impacto e Qualis acima de B1, em contrapartida, todos os outros programas aqui relatados possuem regimentos específicos para publicação de artigos oriundos de teses, sendo pré-requisito para a obtenção do título de doutor.

Observou-se no presente estudo que 38,0\% dos artigos publicados pelos doutores em periódicos foram publicados em revistas de Qualis A2, 20,0\% de Qualis B1 e 10,0\% Qualis B2 (Tabela 5). A FEA USP é uma das universidades responsáveis pelo maior número de publicações e em publicações indexadas em revistas de Qualis superiores, seguidas pelo programa multiinstitucional UnB/UFPB/UFRN. Tais universidades realizaram publicações, em sua maioria, em revistas A2, entretanto, no programa multi-institucional UnB/UFPB/UFRN, FURB, UFPB e UFSC a divulgação maior se deu em periódicos de Qualis B1. 
Tabela 5

Artigos publicados referentes às teses defendidas de 2009 a 2018 (em \%)

\begin{tabular}{|c|c|c|c|c|c|c|c|c|c|c|}
\hline \multirow[b]{2}{*}{ Região } & \multirow[b]{2}{*}{ Programa } & \multicolumn{9}{|c|}{ QUALIS } \\
\hline & & A1 & $\mathbf{A 2}$ & B1 & $\mathbf{B} 2$ & $\mathbf{B 3}$ & B4 & B5 & $\mathbf{C}$ & $\begin{array}{c}\text { Sem } \\
\text { Qualis }\end{array}$ \\
\hline Centro-Oeste & UnB & - & 25 & 25 & 12,5 & 25 & - & - & - & - \\
\hline Nordeste & UFPB & - & - & 33,3 & 33,3 & - & 16,7 & 16,7 & - & - \\
\hline Nordeste/Centro-Oeste & UnB/UFPB/UFRN & - & 39,3 & 7,1 & 7,1 & 14,3 & 8,9 & 3,6 & - & 19,6 \\
\hline \multirow{5}{*}{ Sudeste } & FUCAPE & 50 & - & 50 & - & - & - & - & - & - \\
\hline & UFRJ & 33,3 & 33,3 & - & - & - & 33,3 & - & - & - \\
\hline & UFU & - & 100 & - & - & - & - & - & - & - \\
\hline & FEARP USP & 11,1 & 55,6 & 5,6 & 11,1 & - & - & - & - & 16,7 \\
\hline & FEAA USP & - & 38,6 & 20,7 & 9,3 & 7,9 & 6,4 & 2,1 & 0,7 & 14,3 \\
\hline \multirow{4}{*}{ Sul } & FURB & - & 28,8 & 32,7 & 15,4 & 7,7 & 3,8 & 1,9 & - & 9,6 \\
\hline & UFPR & - & 28,8 & 32,7 & 15,4 & 7,7 & 3,8 & 1,9 & - & 9,6 \\
\hline & UFSC & - & 28,6 & 42,9 & - & - & 14,3 & - & - & 14,3 \\
\hline & UNISINOS & - & 75 & - & - & - & - & - & - & 25 \\
\hline
\end{tabular}

Fonte: Dados da pesquisa (2021).

Nota-se que os discentes buscam cumprir o regramento dos programas ao escolherem o meio de publicação para suas pesquisas, observando a classificação do periódico quanto ao Qualis. Apesar de a FEA USP não condicionar a obtenção do título de doutor a publicações e, consequentemente, a algum Qualis específico, é o programa que se sobressai aos demais em todos as categorias estudadas, exceto na média de publicações por doutor.

No total, 39,0\% dos trabalhos publicados em revistas científicas que possuem relação com a tese foram publicados em periódicos com Qualis de classificação A, resultado semelhante ao que obtiveram Cunha, Cornacchione e Martins (2011) ao estudarem a contribuição dos doutores em Ciências Contábeis quanto à divulgação dos resultados de suas teses, no qual, dos doutores estudados, cerca de $32,0 \%$ de suas publicações foram em periódicos com classificação A. No entanto, 14,0\% (42 artigos) das publicações se deram em periódicos sem classificação, valor menor que o encontrado (41,4\%) por Borba et al. (2007) e maior que Cunha, Cornacchione e Martins (2011) que encontraram 32 artigos (28,8\%) em revistas não classificadas. Importante destacar a afirmação de Suleski e Ibaraki (2009), os quais dizem que raramente artigos publicados em periódicos são divulgados em outros meios.

\subsection{Citações dos produtos da tese}

Para analisar quantos artigos publicados relacionados à tese foram citados em outras pesquisas, os títulos de cada artigo foram inseridos no Google Acadêmico e a partir dele foi possível verificar o número total de citações por trabalho. O presente estudo localizou 302 artigos publicados em periódicos que possuem relação com a tese, tais artigos foram citados 2.392 vezes. Ao analisar o total de citações de tais artigos, aqueles publicados pelos doutores titulados pela FEARP USP correspondem a 50,0\% das citações gerais, seguidos da multiinstitucional UnB/UFPB/UFRN e da FURB, com 15,0\% e 14,0\%, respectivamente (Tabela 6). Por outro lado, os artigos da UFU não foram citados ou não encontrados na busca no Google Scholar. 
Tabela 6

Citações dos artigos relacionados à tese

\begin{tabular}{cccc}
\hline Região & Programa & No de Citações & $\%$ \\
\hline Centro-Oeste & UnB & 24 & 1,0 \\
\hline Nordeste & UFPB & 6 & 0,3 \\
\hline Nordeste/Centro-Oeste & UnB/UFPB/UFRN & 373 & 15,6 \\
\hline Sudeste & FUCAPE & 316 & 13,2 \\
& UFRJ & 8 & 0,3 \\
& UFU & 0 & 0,0 \\
& USP-RP & 1.216 & 50,8 \\
& USP & 86 & 3,6 \\
\hline Sul & FURB & 341 & 14,3 \\
& UFPR & 2 & 0,1 \\
& UFSC & 14 & 0,6 \\
\hline Total Geral & UNISINOS & 6 & 0,3 \\
\hline
\end{tabular}

Fonte: Dados da pesquisa (2021).

Dentro do período estudado, o número de artigos relacionados à tese e publicados apresenta um volume crescente. $\mathrm{O}$ mesmo não acontece com a quantidade de citações, que tem oscilado entre 2007 e 2020, sendo o maior volume localizado em 2016, ano em que 33 artigos foram citados 446 vezes, em média 13 citações por trabalho (Figura 3).

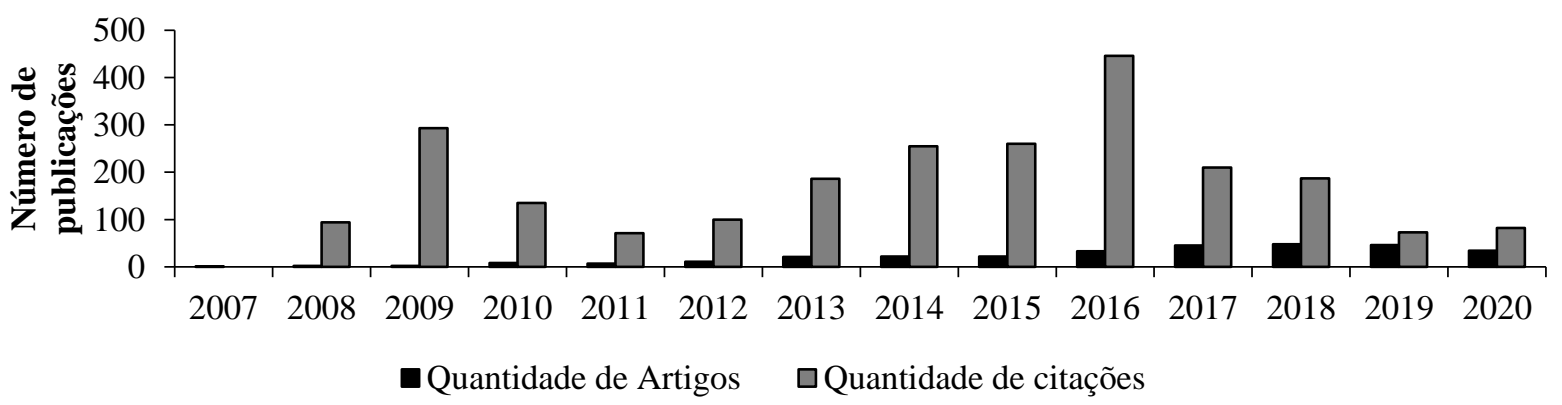

Figura 3. Relação entre artigos e citações de periódicos de 2007 a 2020.

Fonte: Dados da pesquisa (2021).

Ao analisar comparativamente a quantidade de teses defendidas por cada programa e a quantidade de artigos publicados relativos à tese, a FUCAPE e UFRJ apresentam os menores índices de publicação, apenas $28,0 \%$ e $30,0 \%$, respectivamente. Todos os doutores do programa da UFPB publicaram pelo menos um artigo sobre suas teses, bem como FURB, UnB e FEARP USP (Tabela 7).

Tabela 7

Relação entre teses e publicações entre 2009 e 2018

\begin{tabular}{ccccc}
\hline Região & Programa & Teses & Publicações & Publicações \% \\
\hline Centro-Oeste & UnB & 7 & 8 & 114,29 \\
\hline Nordeste & UFPB & 4 & 6 & 150,00 \\
\hline Nordeste/Centro-Oeste & UnB/UFPB/UFRN & 64 & 56 & 87,50 \\
\hline Sudeste & FUCAPE & 7 & 2 & 28,57 \\
\end{tabular}




\begin{tabular}{ccccc} 
& UFRJ & 10 & 3 & 30,00 \\
& UFU & 4 & 2 & 50,00 \\
& FEARP USP & 18 & 18 & 100,00 \\
& FEA USP & 165 & 140 & 84,85 \\
\hline \multirow{3}{*}{ Sul } & FURB & 45 & 52 & 115,56 \\
& UFPR & 10 & 4 & 40,00 \\
& UFSC & 7 & 7 & 100,00 \\
& UNISINOS & 9 & 4 & 44,44 \\
\hline Total Geral & & $\mathbf{3 5 0}$ & $\mathbf{3 0 2}$ & \\
\hline
\end{tabular}

Fonte: Dados da pesquisa (2021).

Do total geral das teses defendidas e suas respectivas publicações em artigos periódicos, verifica-se que a região Sudeste foi a que obteve os maiores índices de publicações. Isso pode estar relacionado a maior quantidade de programas de pós-graduação nas universidades, além de maior investimento de recursos destinados à ciência e tecnologia. Pode-se perceber, portanto, que a marca da assimetria, da hierarquia e da desigualdade ainda é um dos grandes desafios do sistema de pós-graduação no país. Essas assimetrias podem ser observadas tanto em relação às regiões político-administrativas brasileiras, quanto se observa que as regiões Sudeste e Sul, desde o início, recebem mais incentivos.

\section{CONSIDERAÇÕES FINAIS}

Tendo em vista que o objetivo do trabalho foi analisar a evolução da divulgação do conhecimento científico gerado nas teses em Ciências Contábeis no Brasil defendidas nos programas de pós-graduação stricto sensu entre os anos de 2009 a 2018, observou-se 350 teses defendidas durante este período, o que possibilitou a análise de 348 currículos de doutores titulados nos Programas de Pós-graduação em Ciências Contábeis, com o intuito de verificar todas as produções desses doutores, desde sua entrada no doutorado, para que assim, fosse possível mensurar se há e quais os formatos de divulgação das teses.

Os dados levantados demonstram que a divulgação das teses se deu em diferentes formatos, tanto na forma de artigos científicos em periódicos, como em outros meios, tais como: livros, capítulos de livros e congressos científicos. Outro aspecto analisado foi o papel de orientador que os doutores estudados relatam em seus currículos lattes, orientando pesquisas realizadas no âmbito da graduação, mestrado e doutorado.

Constatou-se que as teses estudadas apresentaram divulgação em grande parte em congressos científicos, que corresponderam a $54,71 \%$ de publicações relacionadas às teses. $\mathrm{Na}$ sequência, o meio de divulgação foi a publicação em periódicos científicos, representado por $40 \%$ de artigos comparados ao total das teses. Na sequência, mas já com pouca representatividade, $5,29 \%$ correspondem a livros e capítulos de livros.

Entretanto, quando se compara a quantidade de trabalhos que foram levantados nos currículos lattes, como sendo subproduto das teses, ou mesmo que estejam ligados a elas, com os demais trabalhos científicos desenvolvidos por esses pesquisadores, tais resultados dessa divulgação tornam-se irrisórios. Para ilustrar, dos 5.468 artigos publicados em periódicos, apenas $5,5 \%$ estão relacionados com a temática abordada em suas respectivas teses; e dos 6.687 artigos publicados em anais de congressos, somente $6,1 \%$ estão relacionados com a tese. Esse fato mostra que há lacunas na disseminação do conhecimento científico gerado nos programas de pós-graduação, pois a maioria dos trabalhos não são publicados e, portanto, não existe uma resposta para a sociedade em geral. Especialmente quando se aborda o impacto e a contribuição dessas pesquisas no âmbito social. Essa situação poderia ser melhor trabalhada nos programas de 
pós-graduação, especialmente pelo fato de que a maioria é ofertado por universidades, que em sua essência, devem trabalhar com o tripé ensino, pesquisa e extensão. Assim, cabe uma reflexão de como os resultados das teses podem ser relatados via projetos de extensão.

No entanto, observa-se um crescimento quanto às publicações em periódicos indexados e, com isso, a sociedade em geral, mais especificamente a acadêmica, passa a ter acesso a essas pesquisas. Apesar deste avanço, nota-se que não há um envolvimento do público externo, ou seja, a sociedade em geral. A restrição do grupo de potenciais leitores é uma barreira à ideia de ciência como um bem público, restringe seu acesso a quem poderia usufrui-la. Isso pode estar relacionado ao tipo de escrita que exige termos mais científicos, e, portanto, é necessário que as informações contidas nas teses possam ser de fácil acesso à sociedade, tanto científica, como em geral, criando assim mecanismos e normas para a divulgação dos conhecimentos adquiridos durante esse processo do doutorado e da realização da pesquisa.

Diante disso, cabe a reflexão sobre a importância da divulgação do conhecimento produzido durante os anos utilizados para o desenvolvimento de uma tese, pois, além de todo o esforço físico e psicológico dispendido nas pesquisas, cabe salientar a existência de investimento financeiro para custear todos esses anos de pesquisas, sendo que muitas vezes, parte desses recursos são financiados pela sociedade. Tal fato que incumbe o dever ético e moral de retornar à sociedade o conhecimento por ela financiado, como forma de retribuição, o qual pode ser feito por meio de publicações, sejam elas em periódicos, livros, anais de congressos, palestras, projetos de extensão, ou mesmo, contribuindo para a formação de outros pesquisadores por meio do papel de orientador.

Como limitação para essa pesquisa foi verificado que nem todos os doutores analisados estavam com seus currículos lattes atualizados ou foram detectadas algumas informações que estão dispostas de forma incompleta na plataforma. Alguns doutores sequer incluíram seu curso de doutorado no currículo. No caso das doutoras, observa-se que a mudança de estado civil em alguns casos não foi registrada na plataforma, ou seja, o sobrenome de solteira permanece no currículo, diferindo dos dados disponíveis nos sites das universidades.

Por fim, quando se aborda o impacto e a contribuição dessas pesquisas no âmbito social, verifica-se que as pesquisas contábeis são feitas apenas para alimentar a própria academia. Uma das formas que a Capes encontrou para minimizar esse problema foi a mudança na nova metodologia de avaliação, na qual um dos critérios é o impacto social gerado pelos programas de pós-graduação. Portanto, é importante repensar o objetivo da pesquisa contábil e novas formas de divulgá-la, fugindo das formas tradicionais pautadas pela linguagem formal e quase incompreensível pela sociedade leiga. Sugere-se, então, que meios mais acessíveis, como palestras online, workshop, vídeos, entre outros, possam aproximar diferentes leitores fora da área contábil.

\section{REFERÊNCIAS}

Albagli, S. (1996). Divulgação científica: informação científica para cidadania. Ciência da Informação, 25(3).

Almeida, A. Jr., \& Maciel, R. (2005). Parecer CFE nº 977/65, aprovado em 3 dez. 1965. Revista Brasileira de Educação, 162-173.

Alves, M. F. \& de Oliveira, J. F. (2014). Pós-Graduação no Brasil: do Regime Militar aos dias atuais. Revista Brasileira de Política e Administração da Educação-Periódico científico editado pela ANPAE, 30(2). 
Araujo, A. M. P. (2017). Formação do Professor de Contabilidade: uma proposta pedagógica. Revista de estudios e Investigación en Psicología y Educación, 049-054.

Barata, R. de C. B. (2016). Dez coisas que você deveria saber sobre o Qualis. Revista Brasileira de Pós-Graduação, 13(1), 13-41.

Bardagi, M., Lassance, M. C. P., Paradiso, Â. C., \& Menezes, I. A. (2006). Escolha profissional e inserção no mercado de trabalho: percepções de estudantes formandos. Psicologia Escolar e Educacional, 10(1), 69-82. 2006.

Bardin, L. (2009). Análise de conteúdo (1a ed.). Edições v. 70.

Beuren, I. M. (2009). Como elaborar trabalhos monográficos em contabilidade. São Paulo: Atlas.

Borba, J. A., Souza, F. C. de, Rover, S., \& Murcia, F. D. (2007). Um Olhar nos Currículos Lattes dos Doutores em Controladoria e Contabilidade formados pela Universidade de São Paulo. Anais Congresso da ANPAD, Rio de Janeiro/RS.

Borges, S. H. (2008). A importância do ensino de pós-graduação na formação de recursos humanos para o estudo da biodiversidade no Brasil: um estudo de caso na ornitologia. Biota Neotropica, 8(1), 21-27.

Coordenação de Aperfeiçoamento de Pessoal de Nível Superior [CAPES]. (2021). Cursos Avaliados $e$ Reconhecidos. https://sucupira.capes.gov.br/sucupira/public/consultas/coleta/programa/quantitativos/quantita tivoAreaConhecimento.jsf?areaAvaliacao $=27 . \% 20$ Acesso $\% 20 \mathrm{em}: \% 205 \% 20 \mathrm{de} \% 20 \mathrm{jan} . \% 20 \mathrm{~d}$ e\%202021.

Costa, A. de J. B., \& Lustosa, P. R. (2012). Rankings dos Programas de Pós-graduação em Ciências Contábeis: análise da produção docente em contabilidade gerencial (20002009). Custose @Gronegócio, 8(esp.), 129-152.

Cunha, J. V. A., Cornacchione, E. B. Jr., \& Martins, G. de A. (2011). Contribuições científicas dos doutores em ciências contábeis: uma análise dos currículos lattes. Revista Universo Contábil, 7(2), 85-96.

Cunha, J. V. A. D., Cornacchione, E. B. Jr., \& Martins, G. D. A. (2008). Pós-graduação: o curso de doutorado em ciências contábeis da FEA/USP. Revista Contabilidade \& Finanças, 19, 626.

Dantas, J. A., Silva, C. T., Santana, C. M., \& Vieira, E. T. (2011). Padrões de comunicação científica em contabilidade: um comparativo entre a revista contabilidade e finanças e a the accounting review. Revista Contemporânea de Contabilidade, 8(16), 11-36.

Dias, W. de O., Barbosa Neto, J. E., \& Cunha, J. V. A. da. (2011). A comunicação do conhecimento científico: dados sobre a celeridade do processo de avaliação e de publicação de artigos científicos em periódicos da área de contabilidade. Revista Contemporânea de Contabilidade, 8(15), 41-62. 
Fabre, V. V. \& Bonfante, E. A. (2017). Produção científica sobre contabilidade pública: Estudo bibliométrico dos útimos 10 anos. Anais XIV Congresso USP.

Fávero, M. D. L. D. A. (2006). A Universidade no Brasil: das origens à Reforma Universitária de 1968. Educar em Revista, 17-36.

Frigeri, M., \& Monteiro, M. S. A. (2014). Qualis Periódicos: indicador da política científica no Brasil? Estudos de Sociologia, 37(19), 299-315.

Ganz, A. C. S., Lima, J. P. R., \& Haveroth, J. (2019). Velhos problemas, novos olhares: Etnografia sobre a experiência de futuros doutores em contabilidade. Anais do USP International Conference in Accounting (vol. 19)

Mansur, V., Guimarães, C., Carvalho, M. S., Lima, L. D. D., \& Coeli, C. M. (2021). Da publicação acadêmica à divulgação científica.

Martins, G. de A. (2007). Avaliação das avaliações de textos científicos sobre contabilidade e controladoria. Revista de Educação e Pesquisa em Contabilidade (Repec), 1(1), 1-13.

Martins, O. S., \& Monte, P. A. do. (2009). Um recorte da produção científica dos egressos de um Programa de Pós-Graduação Stricto Sensu em Contabilidade. Revista Contemporânea de Contabilidade, 6(12), 127-150.

Miranda, G. J., Santos, L. de A. A., Nova, S. P. de C. C., \& Cornachione Junior, E. B (2013). A teoria do capital humano e as contribuições acadêmicas dos doutores em ciências contábeis no brasil. Revista Ambiente Contábil, 5(1).

Moutinho, L., Cesarino, P., \& Novaes. S. C. (2019). Momento é de crise. Revista de Antropologia, 6(3).

Mueller, S. P. M. (2002). Popularização do conhecimento científico. Revista de Ciência da Informação, 3(2).

Murcia, F. D., \& Borba, J. A. (2008). Possibilidades de inserção da pesquisa contábil brasileira no cenário internacional: uma proposta de avaliação dos periódicos científicos de contabilidade e auditoria publicados em língua inglesa e disponibilizados no portal de periódicos da capes. Revista Contabilidade \& Finanças, 19(46), 30-43.

Nobre, L. N., \& Freitas, R. R. (2017). A evolução da pós-graduação no Brasil: histórico, políticas e avaliação. Brazilian Journal of Production Engineering, 3(2), 18-30.

Noronha, D. P. (1997). Divulgação de dissertações de mestrado e teses de doutorado em Saúde Pública. Revista Trans Informação, 9(3), 88-103.

Oliveira, J. C. de, Martins, C., Borba, J. A., \& Silva, R. de F. C. da. (2007). Traçando o Perfil dos Pesquisadores em Produtividade (PQ) do Cnpq da Área de Administração e Contabilidade. Anais ENEPQ, Recife, PE. 
Paletta, F. C., Silva, L. G., \& Santos, T. V. A universidade como agente de geração e difusão de Informação, ciência e tecnologia. Pesquisa Brasileira em Ciência da Informação $e$ Biblioteconomia, 9(2).

Peleias, I. R., Silva, G. P. D., Segreti, J. B., \& Chirotto, A. R. (2007). Evolução do ensino da contabilidade no Brasil: uma análise histórica. Revista Contabilidade \& Finanças, 18, 19-32.

Pessoni, A. (2016). A divulgação científica nas universidades do grande ABC: inovações ou repetições de formatos? Comunicação \& Informação, 19(1).

Queiroz, G. B. R., \& Becker, V. (2016). Jornalismo e divulgação científicos nas universidades brasileiras: análise de estratégias para facilitar o acesso à C\&T. Brazilian Journalism Research, 12(3).

Sacardo, M. S., \& Hayashi, M. C. P. I. (2011). Balanço bibliométrico da produção científica em Educação Física e Educação Especial oriunda de teses e dissertações. Revista Brasileira de Pós-Graduação, 8(15), 111-135.

Santos, A. L. F., \& Azevedo, J. M. L. (2009). A pós-graduação no Brasil, a pesquisa em educação e os estudos sobre a política educacional: os contornos da constituição de um campo acadêmico. Revista Brasileira de Educação, 14(42).

Severino, A. J. (2006). A avaliação no PNPG 2005-2010 e a política de pós-graduação no Brasil. In Ferreira, N. S. C. (Ed.).

Silva, F. A. (2020). Ser professor-contador: a competência para atuar no espaço-tempo de sala de aula no ensino superior na formação de contadores. Repositorio de Tesis y Trabajos Finales UAA.

Silva, A. G. da, Morais, F. M. S. G. de, Farias, I. P.; Medeiros, P. M. de, \& Araújo, J. G. N de. (2019). Dificuldades do Docente no Processo de Orientação em Trabalhos de Conclusão de Curso: um estudo em cursos de ciências contábeis em instituições de ensino superior da grande Recife. Revista Evidenciação Contábil \& Finanças, 7(1), 20-38.

Silva, R. S., \& Rodrigues, J. C. (2013). O ensino da contabilidade no Brasil-características e tendências. V Encontro Científico Sul Mineiro de Administração, Contabilidade e EconomiaECOSUL.

Sucupira, N. (2021). Definição e regulamentação de cursos de pós-graduação - Parecer CFE no 977/65. Revista Brasileira de Educação. Recuperador de https://www.scielo.br/j/rbedu/a/NsLTtFBTJtpH3QBFhxFgm7L/?lang=pt\&format=html

Suleski, J., \& Ibaraki, M. (2009). Scientists are talking, but mostly to each other: a quantitative analysis of research represented in mass media. Public Understanding Of Science, 19(1), 115125.

Tanaka, L. M. (2021). Impacto Social de Programas de Pós-graduação no Brasil com Interfaces na Área de Sustentabilidade Urbana. Instituto de Estudos Avançados da Universidade de São Paulo. Recuperado de http://www.iea.usp.br/pesquisa/projetos-institucionais/usp-cidades- 
globais/artigos-digitais/impacto-social-de-programas-de-pos-graduacao-no-brasil-cominterfaces-na-area-de-sustentabilidade-urbana\%3E

Vendramin, E. de O., Lima, J. P. R. de, Santos, I. J. dos, Guasso, M. V. P., \& Fernandes, N. (2020). O que se pesquisa em ensino contábil? Análise do Congresso USP de Contabilidade e Iniciação Científica. Revista Catarinense da Ciência Contábil, 19. https://doi.org/10.16930/2237-766220203107 